九州大学学術情報リポジトリ

Kyushu University Institutional Repository

\title{
Flow in a U-shaped Burrow
}

\section{Mori, Ken}

Laboratory of Bioproduction and Environment Information Sciences, Division of Bioproduction and Environment Information Sciences, Department of Bioproduction Environmental Science, Faculty of Agriculture, Kyushu University

Shikasho, Shiomi

Laboratory of Drainage and Water Environment, Division of Regional Environment Science, Department of Bioproduction Environmental Science, Faculty of Agriculture, Kyushu University

\section{Hiramatsu, Kazuaki}

Laboratory of Drainage and Water Environment, Division of Regional Environment Science, Department of Bioproduction Environmental Science, Faculty of Agriculture, Kyushu University

\section{Takegaki, Takeshi}

Laboratory of Fisheries Biology, Division of Marine Bioresources, Department of Animal and Marine Bioresource Science, Graduate School of Bioresources and Bioenvironmental Sciences, Kyushu University

https://doi.org/10.5109/24376

出版情報: 九州大学大学院農学研究院紀要. 45 (1)，pp. 267-276，2000-11. Kyushu University バージョン：

権利関係 : 


\title{
Flow in a U-shaped Burrow
}

\author{
Ken Mori, Shiomi Shikasho*, Kazuaki Hiramatsu* and Takeshi Takegaki**
}

Laboratory of Bioproduction and Environment Iuformation Sciences, Division of Bioproduction and Environment Information Sciences, Department of Bioproduction Environmental Science,

Faculty of Agriculture, Graduate School, Kyushu University, Fukuoka 812-8581, Japan

* Laboratory of Drainage and Water Environment, Division of Regional Environment Science, Department of Bioproduction Environmental Science, Faculty of Agriculture, Graduate School, Kyushu University, Fukuoka 812-8581, Japan

(Received July 7, 2000 and accepted August 18, 2000)

In this study, we examine the effects of water exchange between the inside and the outside of a burrow with a mound modelled by a U-shaped pipe. We found that the mean velocity in the pipe was closely related not only to the height of a mound and the mean velocity in the flume, but also to the permeability of the mound and the material of which it is made.

\section{INTRODUCTION}

For fishes that burrow, it is very important that the water environment in the burrows stay in good conditions. For example, it is well known that, in a spawning season, Valenciennea longipinnis makes a mound beside the exit or entrance of its burrow by piling up coral pieces and shells (Takegaki et. al., 1999). This behavior serves not only to protect spawn from invaders but also to maintain an appropriate concentration of dissolved oxygen in the burrows. It is thought that the structure of these mounds maintains the burrow's water environments in good conditions by exchanging inner for outer fluids.

In the present study, we examine the effects of water exchange between the inside and the outside of a burrow by conducting hydraulic experiments with mounds modelled by a U-shaped pipe.

\section{METHODS}

\section{Hydraulies in a U-shaped pipe}

Let us take $\mathrm{s}$ and $\mathrm{r}$ axes along and perpendicular to the center axis of the U-shaped pipe, respectively, as shown in Fig. 1. The radius and length of the pipe are $a$ and $\ell$, respectively. Assuming that the flow in the pipe is laminar, the shearing stress is given by the following equation from the equilibrium of forces acting the element of fluid.

$$
\tau=\frac{w r I}{2}=\frac{w r}{2} \frac{\partial}{\partial s}\left(\frac{P}{w}+z\right)
$$

\footnotetext{
** Laboratory of Fisheries Biology, Division of Marine Bioresources, Department of Animal and Marine Bioresource Science, Graduate School of Bioresource and Bioenvironmental Sciences, Kyushu University
} 


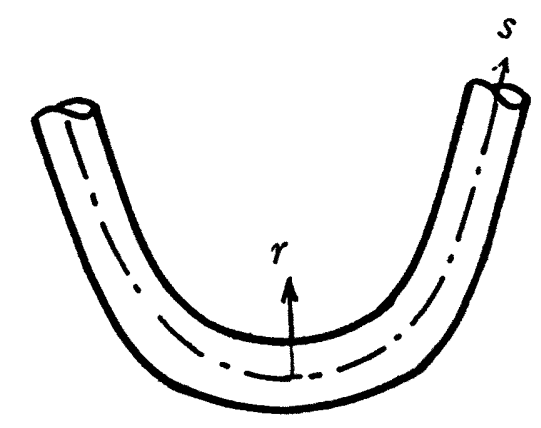

Fig. 1. Axis of coordinates.

in which $\tau$ is the shearing stress, $I$ is the piezometric gradient, $p$ is the pressure, $z$ is the height of datum level and $w$ is the specific weight of water.

As the flow in the pipe is laminar, the definition of shearing stress is given by:

$$
\tau=-\rho \nu \frac{d u}{d r}
$$

in which $\rho$ is the density of the water, $\nu$ is the kinematic viscosity, and $u$ is the velocity at the distance, $r$, from the center of the pipe. The minus sign in eq. (2) implies that the velocity, $u$, decreases as the distance, $r$, increases.

By combining eqs. (1) and (2), it is possible to derive a differential equation for the velocity profile in the pipe:

$$
-\nu \frac{d u}{d r}=\frac{g I}{2} r
$$

Integrating eq. (3) with the velocity, $u=0$, at the wall of the pipe $r=a$,

$$
v=\frac{g I}{42}\left(a^{2}-r^{2}\right)
$$

From eq. (4), therefore, the flow rate, $Q$, through the pipe leads to:

$$
Q=\int_{0}^{a} 2 \pi r u d r=\frac{\pi a^{4} g I}{8 \nu}
$$

The mean velocity in the pipe, $\bar{u}$ is given by:

$$
\bar{u}=\frac{g I a^{4}}{8 \nu}=-\frac{g a^{2}}{8 \nu} \frac{\partial}{\partial s}\left(\frac{P}{w}+z\right)
$$

From eq. (5) with the length of the pipe, $\ell$, the mean velocity in the pipe leads to:

$$
\bar{u}=\frac{a^{2}}{8 \rho \nu \ell}\left(p_{2}-p_{1}\right)
$$

in which $p_{1}$ and $p_{2}$ are the pressure at the entrance of the pipe at points 1 (the mound 


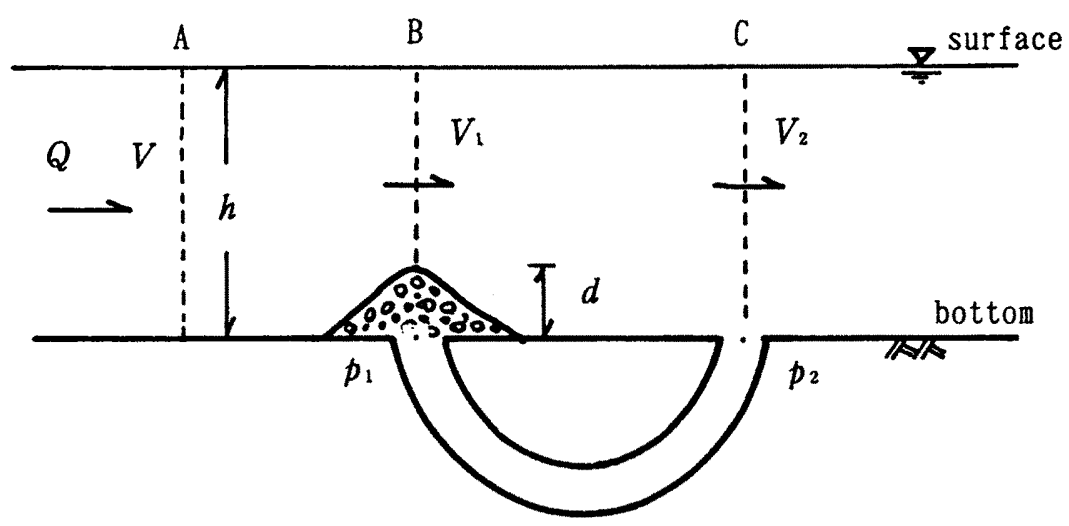

Fig. 2. Sketch of the experimental arrangement.

side) and 2 (the opposite side), respectively, as shown in Fig. 2. Eq. (7) indicates that the magnitude of the mean velocity in the pipe is decided by the difference in pressure between points 1 and 2 (see Fig. 2).

Application of Bernoulli's theorem between sections $\mathrm{B}$ and $\mathrm{C}$ along a streamline in the flume leads to:

$$
\frac{\alpha V_{B}^{2}}{2 g}+\frac{P_{B}}{w}+z_{B}=\frac{\alpha V_{C}^{2}}{2 g}+\frac{P_{C}}{w}+z_{C}+h_{\ell}
$$

in which $a V^{2} / 2 \mathrm{~g}, p / w$ and $z$ are the velocity, the pressure, and the potential heads, respectively; $\alpha$ is the coefficient of energy supplement; and $h_{\ell}$ is the energy loss between sections $\mathrm{B}$ and $\mathrm{C}$. The suffixes $\mathrm{B}$ and $\mathrm{C}$ are sections $\mathrm{B}$ and $\mathrm{C}$, respectively. Neglecting the energy loss, eq. (8) can be written in the form:

$$
\frac{\alpha V_{B}^{2}}{2 g}+\frac{P_{B}}{w}=\frac{\alpha V_{C}^{2}}{2 g}+\frac{P_{C}}{w}
$$

The equation for the continuity of flow rate in the flume can be written in the form:

$$
Q=B h V=B(h-d) V_{B}=B h V_{C}
$$

in which $B$ is the width the flume, $h$ is the depth of the water, and $d$ is the height of the mound.

By combining eqs. (9) and (10) using the relation $\left(p_{2}-p_{1}\right) / w=\left(p_{B}-p_{c}\right) / w$, it is possible to derive the form:

$$
\frac{P_{2}-P_{1}}{w}=\frac{\alpha}{2 g}\left\{\frac{h^{2}}{(h-d)^{2}}-1\right\} V^{2}
$$

Thus, the difference in pressure between points 1 and 2 is proportional to the square of the mean velocity in the flume, and the constant of proportionality is independent of the height of the mound, $d$, and the depth of the water, $h$. If the mound is set up as shown in 
Fig. 2, the difference in pressure between points 1 and $2, p_{2}-p_{1}$, is positive, and then the fluid in the pipe generates to a flow from points 2 to 1 , because the streamlines are concentrated along the near-top of the mound.

Using eqs. (7) and (11), it is possible to derive an expression for the mean velocity in the pipe, $\bar{u}$ :

$$
\frac{\bar{u}}{V}=\left\{\frac{\alpha}{16} \frac{\bar{u} a}{\nu} \frac{a}{\ell}\left[\frac{1}{(1-d / h)^{2}}-1\right]\right\}^{1 / 2}
$$

Eq. (12) indicates that the relative velocity, $\bar{u} / V$, is dependent on the Reynolds number in the pipe, $R_{e}=\bar{u} a / \nu$, and on the aspect ratio, a $\ell$.

\section{Hydraulic experiments on flow in the U-shaped pipe 1) Experimental methods and conditions}

The experiments were performed by setting up a flat plate with a U-shaped, circular pipe (as shown in Fig. 2) in a flume $25 \mathrm{~m}$ long, $0.60 \mathrm{~m}$ wide, and $1.5 \mathrm{~m}$ high. The flat plate is a $2 \mathrm{~m}$ long and $0.60 \mathrm{~m}$ wide plastic plate, and the U-shaped pipe is a $45 \mathrm{~cm}$ long and $4 \mathrm{~cm}$ internal diameter plastic tube. The interval length between pipe openings is $25 \mathrm{~cm}$. The direction of flow in the flume is from left to right (see the direction of the arrow in Fig. 2). We used alumina balls (with diameters of 6,8 and 10 mm) and coral pieces as materials in making the mounds. The mounds were shaped as hexagonal cones. The heights of the mounds were adjusted by varying the number of layers of alumina balls. The characteristics of the mounds used are given in Table 1.

The experiments were performed in the following hydraulic conditions: the water depth and the mean velocity in the flume were $h=20,30 \mathrm{~cm}$ and $V=3.0 \sim 20.0 \mathrm{~cm} / \mathrm{s}$, respectively. Therefore, all the flows in the flume were subcritical (the Froude number, $F_{r}=0.02 \sim 0.12<1$ ). The velocities through the $U$-shaped pipe for various Froude numbers were extremely small. It was impossible to measure the velocities in the pipe using any velocimeter on the market. So, we made a tracer-type velocimeter probe for micro-velocity measurement and used it to measure the velocities in the pipe. The probe consists of a nozzle for tracer injection and two pairs of platinum plate electrodes, which are set up downward from the nozzle. The distance between the nozzle edge and the first electrode, and the distance between the first and second electrodes, are both $1 \mathrm{~cm}$.

The protocol of measurement is: (1) Inject, in pulses, the salt-water tracer from the nozzle. (2) Take the waviness pattern, based on the variation in the resistance of water at each electrode. (3) Measure the time lag, $\mathrm{T}$, from peak to peak of the waviness pattern

Table 1. Characteristics of mounds

\begin{tabular}{crrc}
\hline type & material & height & shape \\
\hline I & alumina ball $(\phi=6 \mathrm{~mm})$ & $5.6 \mathrm{~cm}$ (10 layers) & hexagonal cone \\
II-1 & $(\phi=8 \mathrm{~mm})$ & $3.3 \mathrm{~cm}$ ( 5 layers) & " \\
II-2 & $(\phi=8 \mathrm{~mm})$ & $4.0 \mathrm{~cm}$ ( 6 layers) & " \\
II-3 & $(\phi=8 \mathrm{~mm})$ & $5.3 \mathrm{~cm}$ ( 7 layers) & " \\
III & $(\phi=10 \mathrm{~mm})$ & $4.7 \mathrm{~cm}$ ( 5 layers) & ", \\
IV & coral pieces & $5.0 \mathrm{~cm}$ & \\
\hline
\end{tabular}




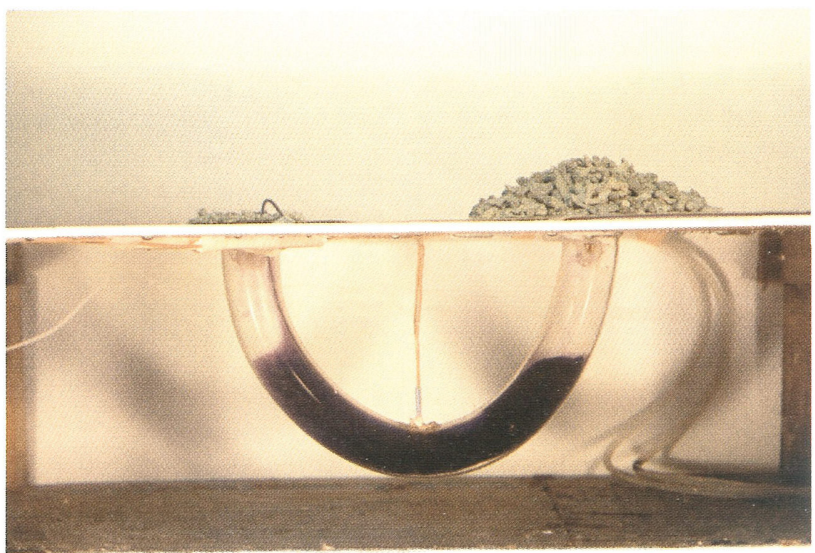

(a) before experiment

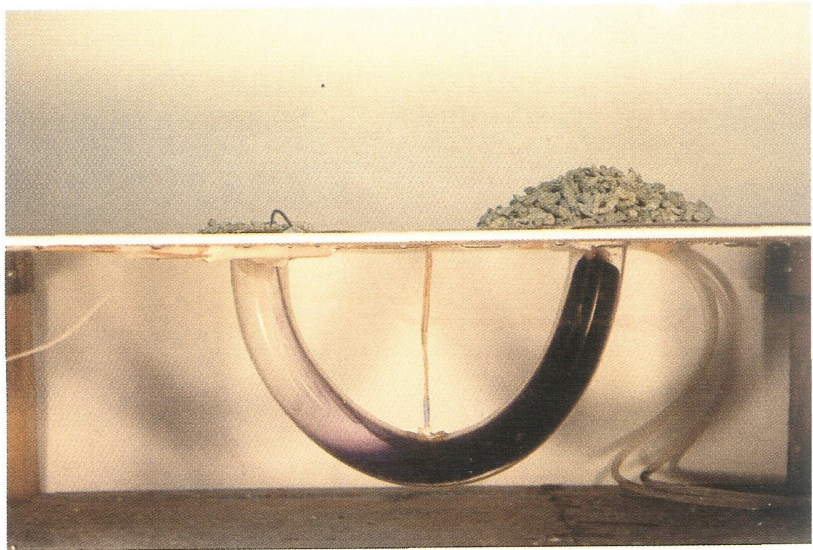

(b) after 25 seconds
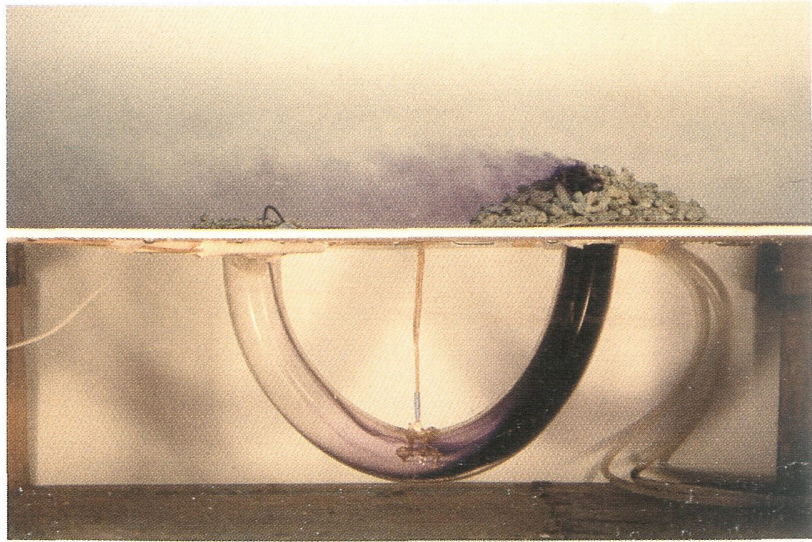

(c) after 50 seconds

Photo 1. Visualized flow in a U-shaped pipe using dye solution. 
obtained from each electrode. (4) Finally, determine the velocity along the axis of the pipe, $\mathrm{Vp}$, by dividing the lag time, $\mathrm{T}$, by the distance between the first and second electrodes, L. If the flow in the pipe is laminar, then the velocity measured by the probe is twice the mean velocity in the pipe. The probe is able to measure micro-velocity on the magnitude of $0.1 \mathrm{~cm} / \mathrm{s}$.

On the other hand, we used an electromagnetic velocimeter (Kennek, Inc.) to measure the vertical profiles of velocity in the flume at any section along the center-line of the flume.

\section{2) Results}

Photo 1 shows the visualized flows in the U-shaped pipe using dye solution, with Aniline Blue for the case of the mound using coral pieces (Type IV). Photo 1(a) shows that the fluid in the U-shaped pipe is at rest, because the difference in pressure between two openings in the pipe is too small to move it. The difference in pressure between points 1 and 2 (see Fig. 2) gradually increases with increasing velocity in the flume, and the difference in pressure is finally large enough to generate movement of the fluid in the pipe. Thus, the fluid in the pipe discharges from the near-top of the mound (see Photo $1(b)$ and (c)) and is exchanged for the fluid in the flume by the inflow from the flume to

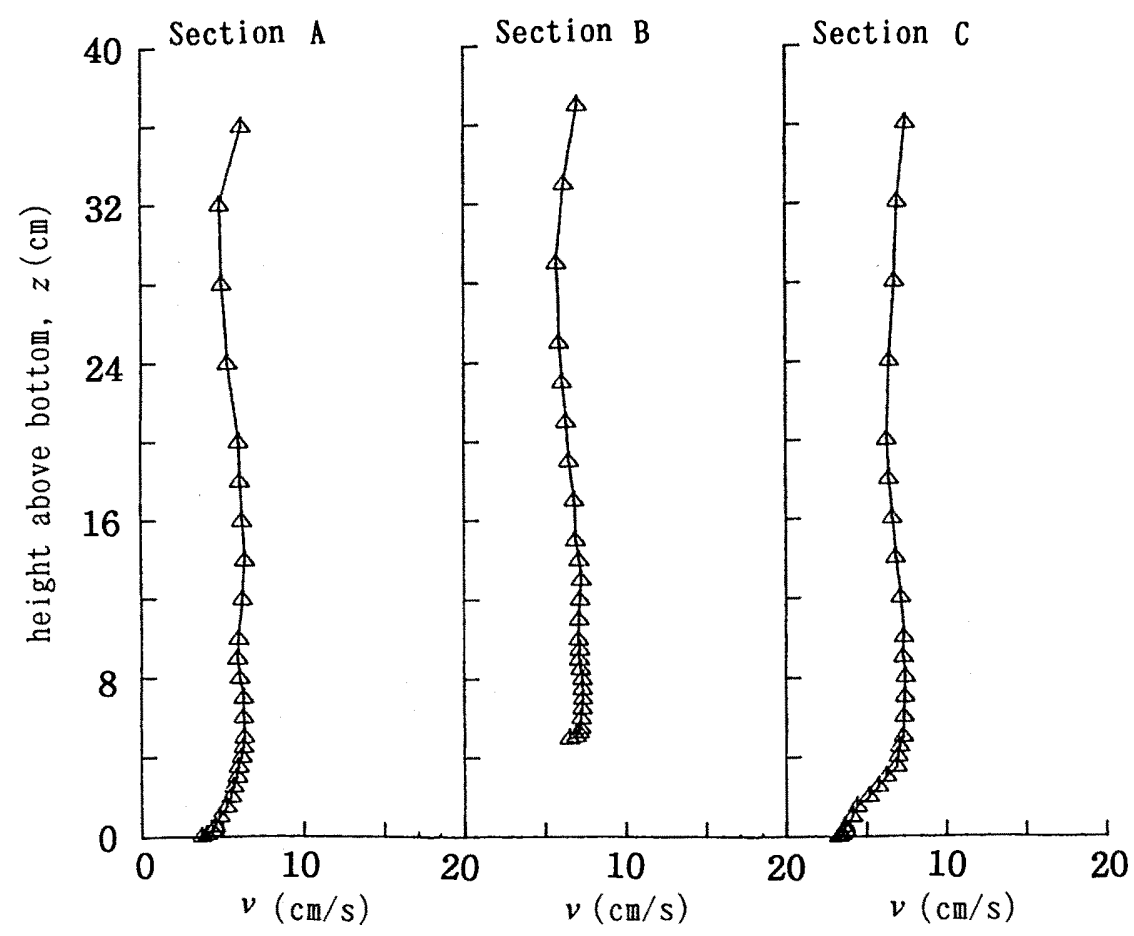

Fig. 3. Vertical distributions of velocity in the flume. 
the pipe to compensate for the discharge. It is noted that the difference in pressure between points 1 and 2 generates the flow in the pipe.

Fig. 3 shows the vertical distributions of the velocity in the flume measured at sections A, B, and C, as shown in Fig. 2. Fig. 3 shows that the vertical profiles of established turbulence shear flow in the upper stream are accelerated at the near-top of the mound.

Fig. 4 shows the experimental results on the relationship between the mean velocity in the U-shaped pipe, $\bar{u}$, and the mean velocity in the flume, $V$, for various mound heights (Types II-1, II-2, II-3 and IV; see Table 1). This velocity, $\bar{u}$, is a scaling factor for the magnitude of the exchange flow rate between the inside and the outside of the pipe. The results shown in Fig. 4 can be used to examine the effect of the height of a mound on the velocity in the pipe.

Fig. 5 also shows the results on the relationship between the mean velocity in the pipe and the mean velocity in the flume for various diameters of alumina ball used to make up the mounds (Types I, II-3, III; see Table 1). The results can also be used to examine the effect of the permeability of a mound on the velocity in the pipe.

Fig. 6 shows the results obtained on the effect of the water depth in the flume on the velocity in the pipe (Type II-3; see Table 1).

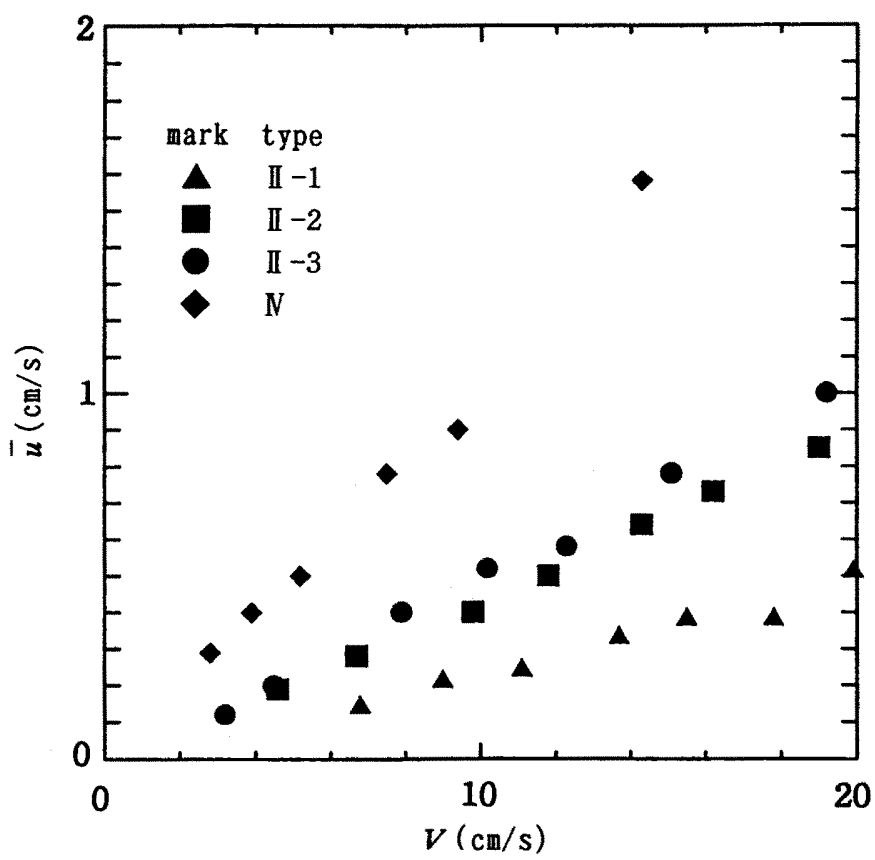

Fig. 4. Relationship between mean velocity in the U-shaped pipe and mean velocity in the flume for various heights of mound. 
Fig. 4 shows that the mean velocity in the pipe increases as the mean velocity in the flume increases, because the difference in pressure between points 1 and 2 increases with increasing velocity in the flume. It is clear from the figure that the relationship between the mean velocity in the pipe and the mean velocity in the flume is satisfied the linearity (Allanson et. al., 1992), and then this relation is in good agreement with eq. (12).

Fig. 5 shows that the mean velocity in the pipe is little influenced by the permeability of the mound if the mean velocity in the flume is small. However, when the mean velocity in the flume is over $10 \mathrm{~cm} / \mathrm{s}$, the mean velocity in the pipe is remarkably influenced by the permeability of the mound. Especially, the effect of permeability in the case of Type $\mathrm{II}$ is remarkable, even though that mound is lower than others. In the results for Types I and II, the relations between the mean velocity in the pipe and the mean velocity in the flume offset the effect of permeability against the height of either mound. Fig. 4 also shows that the mound made by nonuniform coral pieces has a remarkable permeability effect on the mean velocity in the pipe.

Fig. 6 shows that the effect of water depth is less in the present experiments than the effect of permeability.

These results indicate that the mean velocity in the pipe is closely related not only to the height of the mound and the mean velocity in the flume but also to the permeability

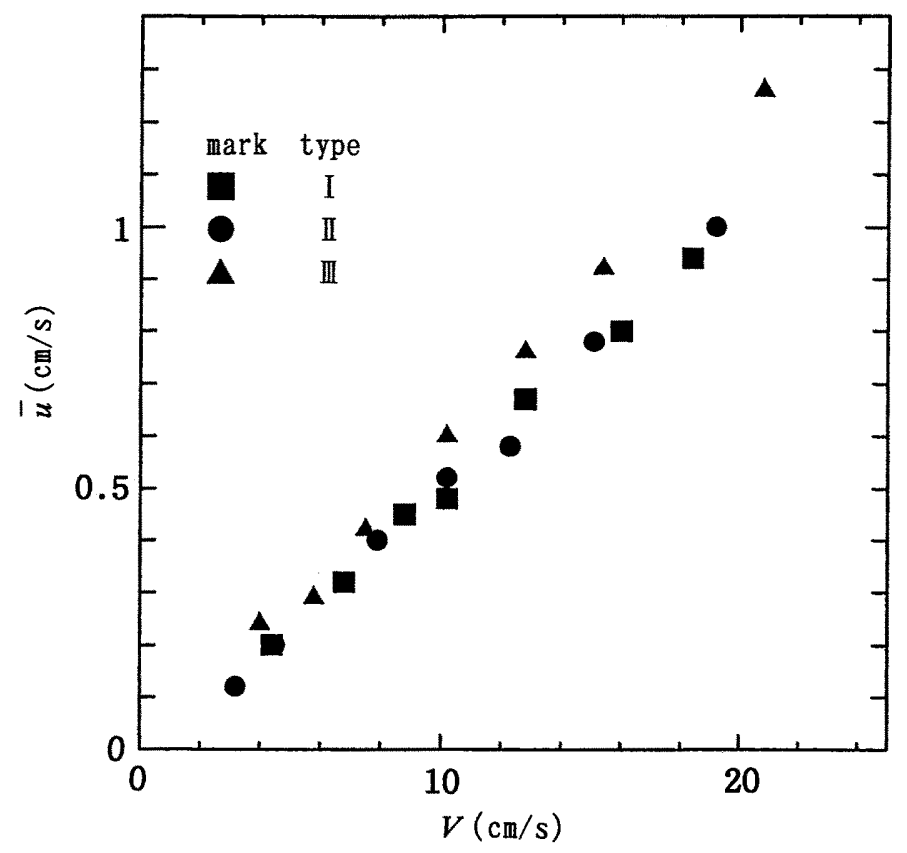

Fig. 5. Relationship between mean velocity in the U-shaped pipe and mean velocity in the flume for various permeabilities of mound. 


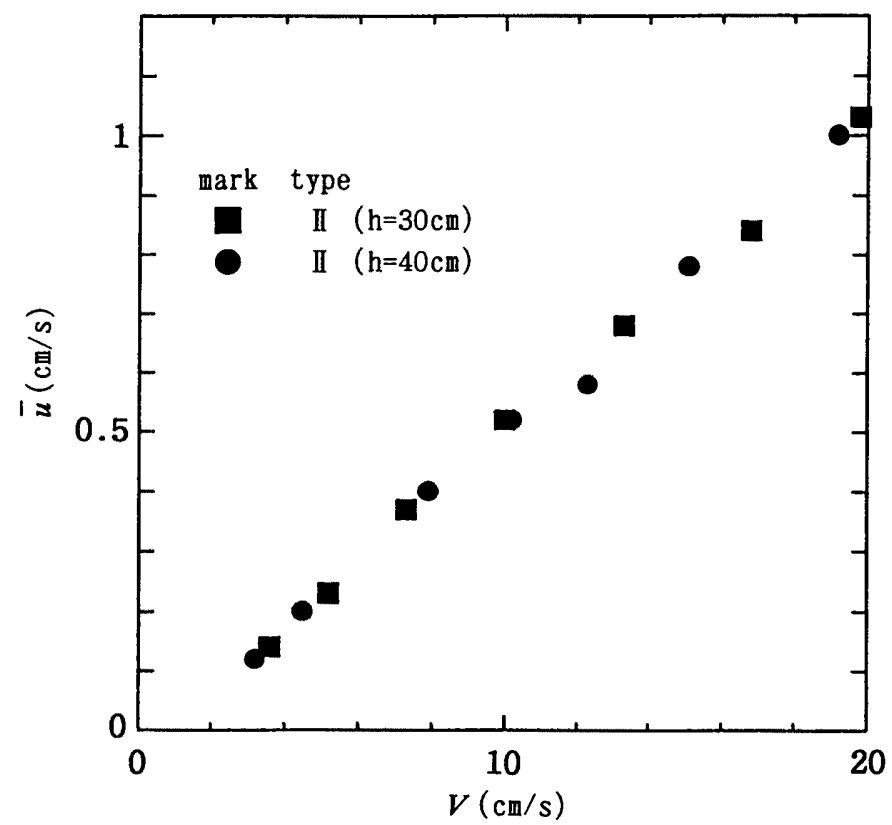

Fig. 6. Relationship between mean velocity in the U-shaped pipe and mean velocity in the flume for various water depths.

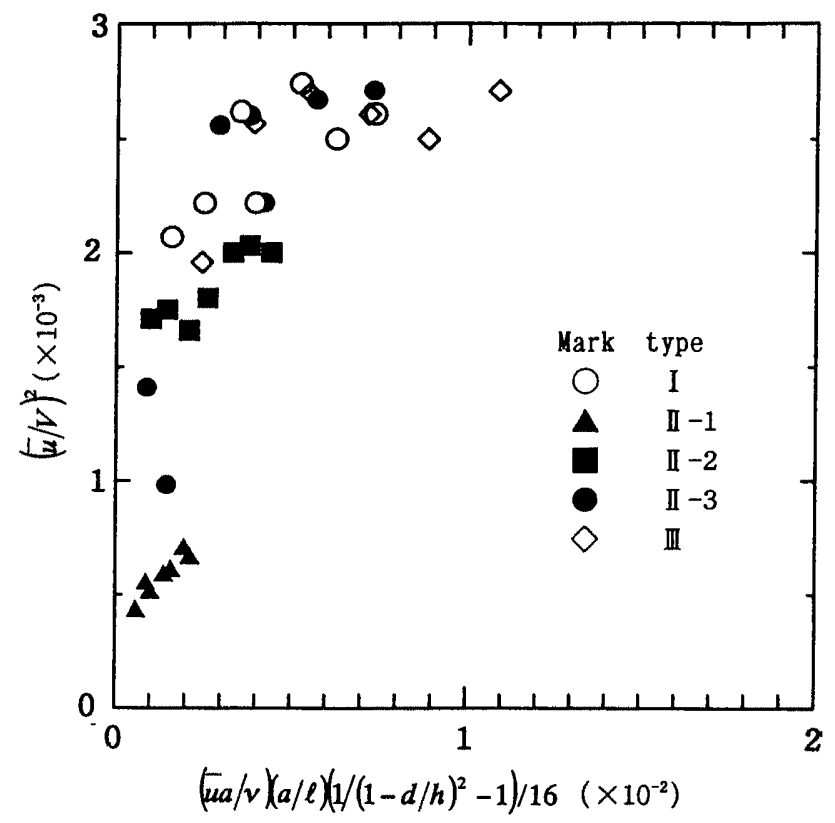

Fig. 7. Regression of relative mean velocity, $\bar{u} / \mathrm{V}$, on the product of Reynolds number in the U-shaped pipe, $R_{e}=\bar{u} a / \nu$, aspect ratio, a/ $\ell$, and relative water depth, $d / h$. 
and the material of the mound.

Fig. 7 also shows the comparison of eq. (12) with the experimental data. It is found from the figure that eq. (12) is in good agreement with the experimental data. As eq. (12) does not consider the effect of the permeability of the mound, we should introduce the expression corresponding to eq. (12) with that effect.

\section{CONCLUSIONS}

We obtained the following conclusions in the present study:

(1) The flow in a burrow with a mound modelled by a U-shaped pipe is generated by the difference in pressure between the entrance and exit of the burrow.

(2) The magnitude of the mean velocity in the U-shaped burrow depends on the mean velocity in the flume, the height of the mound, and the permeability of the mound.

(3) Eq. (12) introduced by neglecting energy loss is in good agreement with experimental data.

\section{REFERENCES}

Allanson B. R., D. Skimmer and J. Imbeger 1992 Flow in Prawn Burrows, Estuarine, Coastal and Shelf Science 35: 253-268

Takegagi T., K. Mori, S. Shikasho and A. Nakazono 1999 Effect of mound structure on water exchange in Valenciennea longipinnis burrow, Fisheries Engineering 36•1: 87-90 (in Japanese) 